\title{
Usabilidade da gestão de projetos em ações de extensão em universidade pública federal: mapeamento, desafios e oportunidades
}

Usability of project management in extension actions in federal public universities: mapping, challenges and opportunities

\author{
Edicleia Aparecida Muniz dos Santos ${ }^{1}$ \\ Jair de Oliveira ${ }^{2}$ \\ Ariel Orlei Michaloski ${ }^{3}$
}

\section{RESUMO}

A extensão universitária promove a interação entre Universidade e sociedade, estimulando a disseminação do conhecimento, conjuntamente, com impacto na formação do estudante. $\mathrm{O}$ objetivo deste estudo é analisar o gerenciamento dos projetos de extensão de uma instituição federal de ensino localizada no sul do Brasil, buscando identificar as fases em que ocorrem mais problemas em relação à gestão dos projetos. O método de pesquisa caracteriza-se como de cunho exploratório, identificando variáveis que podem gerar hipóteses para pesquisas futuras. O trabalho baseia-se na abordagem qualitativa. A investigação e a análise institucional deram-se a partir de técnica de coleta de dados, fundamentando-se nos princípios da análise documental, adotando como objeto documentos de projetos, planilhas, relatórios, editais de seleção dos projetos de extensão e Sistema SAP, todos internos à instituição. Em conclusão, aponta-se que, atualmente, a gestão dos projetos de extensão dentro do campus é funcional, contudo, é necessário um aprimoramento e aprofundamento nas partes gerenciais, na capacitação dos coordenadores e equipes envolvidas para maior sucesso nos trabalhos desenvolvidos. Ao final, o trabalho abre possibilidades para a continuidade da pesquisa sobre os temas abordados.

Palavras-chave: Extensão universitária. Gestão de projetos. Creditação da extensão.

\begin{abstract}
The university extension promotes the interaction between university and society, stimulating the dissemination of knowledge, jointly, with an impact on student education. The objective of this study is to analyze the management of extension projects of a federal educational institution located in southern Brazil, seeking to identify the phases in which most problems occur in relation to project management. The research method in this study is characterized as exploratory, identifying variables that may generate hypotheses for future research. The work is based on the qualitative approach. The research and institutional analysis were based on data collection technique based on the principles of document analysis, adopting as object the

1 Mestranda no Programa de Administração Pública em Rede Nacional (PROFIAP) na Universidade Tecnológica Federal do Paraná, Campus Cornélio Procópio, Brasil; servidora técnico-administrativa do Departamento de Extensão dessa instituição (edicleiamuniz@utfpr.edu.br).

${ }^{2}$ Doutor em Engenharia de Produção pela Universidade de São Paulo, Brasil; professor titular da Universidade Tecnológica Federal do Paraná, Campus Cornélio Procópio, Brasil; professor no Programa de Administração Pública em Rede Nacional (PROFIAP) (jair@utfpr.edu.br).

${ }^{3}$ Doutor em Engenharia de Produção pela Universidade Federal de Pernambuco, Brasil; professor titular da Universidade Tecnológica Federal do Paraná, Campus Ponta Grossa; professor no Programa de Administração Pública em Rede Nacional (PROFIAP) e no Programa de Engenharia de Produção (PPGEP); pesquisador no Laboratório de Ergonomia em Processos Produtivos e Segurança e Saúde do Trabalho (LabErgo). (ariel@utfpr.edu.br).
\end{abstract}


project documents, spreadsheets, reports, project selection notices, extension and SAP System, all internal to the institution. In conclusion it is pointed out that the current management of extension projects within the campus is functional, however, it is necessary to improve and deepen the management parts, the qualification of the coordinators and teams involved for greater success in the developed work. At the end, the work opens possibilities for the continuity of the research on the topics covered.

Keywords: University Extension. Project management. Extension Credit.

\section{INTRODUÇÃO}

A extensão universitária é indissociável do ensino e da pesquisa dentro das universidades (FORPROEX, 2012; BRASIL, 1988). Dentre os principais desafios presentes na gestão da extensão em universidades, destacam-se a melhoria contínua da relação estudante-professorcomunidade, a busca por técnicas e procedimentos inovadores, e o desenvolvimento de metodologias participativas, que façam a integração do conhecimento com a formação cidadã dos agentes envolvidos.

Nesse contexto, para consolidar esse importante eixo da universidade, foi promulgada a Lei $\mathrm{n}^{\circ}$ 13.005, em 25 de junho de 2014, aprovando o Plano Nacional de Educação (PNE 2014-2024). O PNE estabeleceu na meta 12, a estratégia 12.7 de "assegurar, no mínimo, $10 \%$ (dez por cento) do total de créditos curriculares exigidos para a graduação em programas e projetos de extensão universitária, orientando sua ação, prioritariamente, para áreas de grande pertinência social” (BRASIL, 2014). Isso significa que todos os alunos dos cursos de graduação deverão cumprir, no mínimo, $10 \%$ da carga horária total do curso em projetos ou programas de extensão, desenvolvendo atividades voltadas à comunidade externa. Destaca-se que não é uma mera participação do estudante em projeto, mas o aluno como protagonista da ação, atuando na organização e execução.

Assim, é importante compreender e trabalhar a gestão de projetos no âmbito das universidades, uma vez que eles estão presentes não só em projetos de extensão, de pesquisa ou de ensino, mas também na infraestrutura, expansão, modernização, abertura de novos cursos, e outros. Afinal, todo projeto é "um esforço para se alcançar um objetivo específico por meio de um conjunto único de tarefas inter-relacionadas e da utilização eficaz de recursos” (CLEMENTS; GIDO, 2013, p. 4).

Nesse sentido, o objetivo deste estudo é analisar o gerenciamento dos projetos de extensão em um campus de uma universidade federal. A pesquisa abrangeu uma análise documental de editais de seleção de propostas, cópias dos projetos, relatórios e planilhas. Buscou-se 
identificar as etapas em que ocorrem mais problemas em relação à gestão dos projetos. Como metodologia, foram utilizados os processos de gerenciamento propostos pelo Project Management Body of Knowledge (PMBOK), do Project Management Institute (PMI). Assim, espera-se que esse estudo contribua para melhoria dos processos de gestão de projetos de extensão no âmbito das universidades.

O trabalho está estruturado em cinco partes: introdução; fundamentação teórica; metodologia; apresentação dos dados e discussão; e considerações finais. A introdução aborda uma visão geral do trabalho. Na fundamentação teórica, são apresentados os principais conceitos relacionados à gestão de projetos e à extensão universitária. Na metodologia, é caracterizado o objeto de estudo e como ocorreu o procedimento da pesquisa. Na sequência, são apresentados e discutidos os resultados. Por fim, nas considerações finais, apresentam-se as contribuições, limitações e possíveis caminhos a percorrer.

\section{FUNDAMENTAÇÃO TEÓRICA}

Nesta seção, são abordados os principais conceitos sobre gestão de projetos e Guia PMBOK. Após, contextualiza-se a extensão universitária no Brasil e na Universidade Tecnológica Federal do Paraná (UTFPR), ressaltando sua proposta de promover o desenvolvimento regional a partir do ensino, da pesquisa e da extensão. Por último, há a explicação sobre as principais fases do projeto de extensão nessa instituição.

\section{Gestão de projetos}

O Gerenciamento de Projetos tem sido utilizado no mundo todo desde muito tempo atrás, como exemplos, as Pirâmides de Gizé, o Taj Mahal, o desenvolvimento de aviões comerciais, os Jogos Olímpicos, a colocação da Estação Espacial Internacional na órbita da Terra, dentre outras (PMI, 2017). Essa longa trajetória mostra a importância da gestão de projetos; assim, constituiu um tema presente na vida empresarial. Quarti e Zilli (2019, p. 151) destacam essa trajetória de evolução, já que a gestão de projetos é debatida “desde a década de 60, porém era vista apenas como um processo inovador, mas não crucial para o sucesso e sustentabilidade das empresas". Contudo, após as recessões econômicas sofridas pelas empresas norteamericanas, houve uma reestruturação em que a ideia da gestão de projetos se tornou essencial para sua sobrevivência. 
Para compreensão da gestão de projeto, recorre-se, primeiramente, aos conceitos relacionados a projetos. Segundo o Guia PMBOK (PMI, 2017, p. 4), "projeto é um esforço temporário empreendido para criar um produto, serviço ou resultado único", ou seja, todo projeto é um empreendimento com início e fim, que deve entregar um resultado. Os projetos devem cumprir objetivos, e "um objetivo é definido como um resultado a que o trabalho é orientado, uma posição estratégica a ser alcançada ou um propósito a ser atingido, um produto a ser produzido ou um serviço a ser realizado" (PMI, 2017 p. 4). Clements e Gido (2013, p. 4) definem projeto como "um esforço para se alcançar um objetivo específico por meio de um conjunto único de tarefas inter-relacionadas e da utilização eficaz de recursos". Destacam que o projeto deve ter um objetivo claro, em que a equipe deve produzir e entregar resultados dentro do tempo e orçamento estipulados. O projeto utiliza recursos, podendo incluir pessoas, organizações, materiais, equipamentos e instalações, e o uso eficaz desses recursos também contribuirá para o sucesso do projeto.

Com o conceito de projeto definido, parte-se para a compreensão da importância da Gestão de Projetos. De acordo com o PMI (2017, p. 10), "gerenciamento de projetos é a aplicação de conhecimentos, habilidades, ferramentas e técnicas às atividades do projeto a fim de cumprir os seus requisitos". Isso possibilita "que as organizações executem projetos de forma eficaz e eficiente" (PMI, 2017, p. 10). Corroborando essa ideia, Clements e Gido (2013, p. 13) definem que "gestão de projetos significa planejar, organizar, coordenar, liderar e controlar recursos para concretizar o objetivo do projeto". Ou seja, é necessário um esforço no planejamento para se obter sucesso no projeto.

Portanto, os conceitos de gestão de projetos são inúmeros, mas, essencialmente, a gestão de projetos envolve planejar, executar e controlar de maneira eficaz e eficiente as atividades necessárias para entrega do produto ou serviço, utilizando recursos e custos definidos, satisfazendo assim, a expectativa de qualidade das partes interessadas.

\section{Guia PMBOK}

O Guia do Conhecimento em Gerenciamento de Projetos (Guia PMBOK) foi criado pelo Project Management Institute (PMI). Esse guia identifica um subconjunto de conhecimentos em gerenciamento de projetos, reconhecido como boas práticas, e também fornece e promove um vocabulário comum para se discutir, escrever e aplicar o gerenciamento de projetos, possibilitando o intercâmbio eficiente de informações entre os profissionais de gerência de 
projetos. É baseado em processos e subprocessos para descrever de forma organizada o trabalho a ser realizado durante o projeto. A primeira edição do Guia PMBOK foi lançada em 1996, e sua última atualização (6 ${ }^{\mathrm{a}}$ edição) foi lançada em 2017.

De acordo com PMI (2017), o Guia PMBOK é formado por componentes-chave, os quais se relacionam durante o gerenciamento do projeto. Quando gerenciados de maneira eficaz, asseguram o sucesso ao final do projeto. Esses componentes são: o ciclo de vida do projeto, grupos de processos e as dez áreas de conhecimento em Gerenciamento de Projetos.

O ciclo de vida de um projeto é "a série de fases pelas quais um projeto passa, do início à conclusão. Ele fornece a estrutura básica para o gerenciamento do projeto. Essa estrutura básica se aplica, independentemente, do trabalho do projeto específico envolvido" (PMI, 2017, p. 19). Segundo Clements e Gido (2013, p. 8), "o ciclo de vida genérico do projeto tem quatro fases: iniciação, planejamento, realização e encerramento". Sendo que cada fase demandará tempo e esforço proporcionais ao tamanho do projeto.

Para o PMI (2017, p. 22) “o ciclo de vida do projeto é gerenciado através da execução de uma série de atividades de gerenciamento de projeto, conhecidas como processos de gerenciamento de projetos". Esses processos podem gerar uma ou mais saídas e necessitar de uma ou mais entradas, utilizando "técnicas e ferramentas de gerenciamento de projetos apropriadas. A saída pode ser uma entrega ou um resultado" (PMI, 2017, p. 22). Ou seja, o resultado é um produto final de um processo.

De acordo com Guia PMBOK (6 ${ }^{\text {a }}$ edição) publicado em 2017, o conhecimento de gerenciamento de projetos consiste em 5 grupos de processos, 49 processos e 10 áreas de conhecimento (integração, escopo, cronograma, custos, qualidade, recursos, comunicações, riscos, aquisições e partes interessadas). Os processos de gerenciamento são agrupados logicamente em cinco grupos listados abaixo, de acordo com o PMI (2017, p. 23):

1. Grupo de processos de iniciação. Os processos realizados para definir um novo projeto ou uma nova fase de um projeto existente, a partir da obtenção de autorização para iniciar o projeto ou fase.

2. Grupo de processos de planejamento. Os processos realizados para definir um novo projeto ou uma nova fase de um projeto existente, por meio da obtenção de autorização para iniciar o projeto ou fase.

3. Grupo de processos de execuçãa. Processos realizados para concluir o trabalho definido no plano de gerenciamento do projeto para satisfazer os requisitos do projeto. 
4. Grupo de processos de monitoramento e controle. Os processos exigidos para acompanhar, analisar e controlar o progresso e desempenho do projeto, identificar quaisquer áreas nas quais serão necessárias mudanças no plano, e iniciar as mudanças correspondentes.

5. Grupo de processos de encerramento. Os processos realizados para concluir ou fechar formalmente um projeto, fase ou contrato.

Há vários estudos demonstrando que a utilização de boas práticas para gerenciamento de projetos é um fator importante para contribuir com seu sucesso. Portanto, é necessário trabalhar a gestão de projetos dentro das universidades, utilizando dessas ferramentas não só no âmbito administrativo, mas também no ensino, na pesquisa e na extensão.

\section{Extensão universitária}

Nesta seção, é abordado um breve histórico sobre a extensão universitária no Brasil e na UTFPR, bem como as fases do projeto de extensão na UTFPR-CP.

\section{Breve histórico}

Em seu contexto histórico, o Brasil vem transformando seu modo de definir e pensar as atribuições da Universidade na sociedade (FLORIANO et al., 2017). Assim, a extensão universitária no Brasil, passou por diversas situações ao longo de sua história. Destacaremos os marcos principais. De acordo com a Política Nacional de Extensão Universitária (FORPROEX, 2012, p. 12), a realização de atividades de extensão universitária, no Brasil, data-se do início do século XX, coincidindo com a criação do Ensino Superior. Como primeiras manifestações, foram realizados cursos e conferências na antiga Universidade de São Paulo, em 1911, e as prestações de serviço da Escola Superior de Agricultura e Veterinária de Viçosa na década de 1920.

Em 1968, foi promulgada a Lei n. 5.540, de 28 de novembro de 1968, conhecida como Lei Básica da Reforma Universitária. Essa Lei estabeleceu, em seu Art. 20, que "as universidades e as instituições de ensino superior estenderão à comunidade, sob a forma de cursos e serviços especiais, as atividades de ensino e os resultados da pesquisa que lhes são inerentes" (BRASIL, 1968). Registra, também, em seu Art. 40, que as instituições de ensino superior deverão possibilitar aos estudantes, por meio de atividades de extensão, participar de 
"programas que visem à melhoria das condições de vida da comunidade e no processo geral de desenvolvimento" (BRASIL, 1968).

Em novembro de 1987, foi criado o Fórum Nacional de Pró-Reitores de Extensão das Universidades Públicas Brasileiras (FORPROEX), que propiciou à comunidade acadêmica condições para redefinição da extensão universitária. Atualmente, o FORPROEX é denominado Fórum de Pró-Reitores de Extensão das Instituições Públicas de Educação Superior Brasileiras.

A Constituição Federal de 1988, em consonância com as definições pactuadas no FORPROEX, em seu Art. 207, estabelece que "as universidades gozam de autonomia didático-científica, administrativa e de gestão financeira e patrimonial, bem como obedecerão ao princípio da indissociabilidade entre ensino, pesquisa e extensão" (BRASIL, 1988). Ou seja, as universidades devem proporcionar aos estudantes acesso ao ensino, à pesquisa e à extensão.

Em 25 de junho de 2014, foi promulgada a Lei $\mathrm{n}^{\circ}$ 13.005, aprovando o Plano Nacional de Educação (PNE) para o período 2014-2024. A meta 12, estratégia 12.7, do documento prevê que as universidades devem "assegurar, no mínimo, 10\% (dez por cento) do total de créditos curriculares exigidos para a graduação em programas e projetos de extensão universitária, orientando sua ação, prioritariamente, para áreas de grande pertinência social” (BRASIL, 2014).

Percebe-se que todos esses acontecimentos culminaram na valorização da extensão para a comunidade acadêmica e para a sociedade. Todavia, ainda há um longo caminho a percorrer, tendo em vista os objetivos a se alcançar, como a introdução da extensão nos currículos da graduação e os desafios nos contextos nacional e internacional, como instabilidade política, diminuição orçamentária e mudanças na legislação.

\section{Extensão e a UTFPR}

A Política Nacional de Extensão define que a extensão universitária “é um processo interdisciplinar, educativo, cultural, científico e político que promove a interação transformadora entre Universidade e outros setores da sociedade" (FORPROEX, 2012, p. 28).

A Extensão Universitária tornou-se o instrumento por excelência de interrelação da Universidade com a sociedade, de oxigenação da própria 
Universidade, de democratização do conhecimento acadêmico, assim como de (re)produção desse conhecimento por meio da troca de saberes com as comunidades. Uma via de mão dupla ou, como se definiu nos anos seguintes, uma forma de "interação dialógica" que traz múltiplas possibilidades de transformação da sociedade e da própria Universidade Pública. (FORPROEX, 2012, p. 17).

A UTFPR, em consonância com a Política Nacional de Extensão criou as Diretrizes de Extensão e o Regulamento de Programas e Projetos de Extensão da Universidade Tecnológica Federal do Paraná (UFTPR, [20--]). As Diretrizes de Extensão da UTFPR estabelecem os seguintes princípios: articulação entre as ações de extensão, ensino e pesquisa, impacto na formação do estudante, interdisciplinaridade, produção de conhecimento, relação social de impacto e relação dialógica entre universidade e sociedade (UFTPR, [20--], p. 2-3).

As ações de extensão dentro da UTFPR são desenvolvidas por meio de programas, projetos, apoio tecnológico, cursos de qualificação profissional, eventos de extensão e acompanhamento de egressos (UFTPR, [20--], p. 5-6). Em atendimento à legislação vigente e à meta 12, a UTFPR estabeleceu, em $1^{\text {o }}$ de outubro de 2018, a Resolução n ${ }^{\circ}$ 69/2018 COGEP, a qual aprova o regulamento de registro e de inclusão das atividades de extensão nos currículos dos cursos de graduação da UTFPR. Assim, os cursos de graduação dessa instituição terão três anos para se adequar ao disposto na Resolução (UFTPR, 2018, p. 2-3).

A UTFPR como universidade tem apenas 13 anos, mas como instituição de ensino já completou 110 anos. A extensão vem crescendo e se fortalecendo junto com a instituição ao longo desse tempo. Atualmente, a extensão é reconhecida pela sociedade como um importante serviço prestado à comunidade. A seguir, são apresentados os procedimentos realizados em cada fase do projeto de extensão na UTFPR-CP.

\section{Fases do projeto de extensão na UTFPR}

Assim como qualquer outro, o gerenciamento do projeto de extensão também pode ser dividido em etapas ou fases, que podem ser sequenciais, iterativas ou sobrepostas. Todo projeto deve ter um gerente, sendo definido pelo PMI (2017, p. 52) como "a pessoa designada pela organização executora para liderar a equipe responsável por alcançar os objetivos do projeto". Na UTFPR, é utilizado o termo coordenador, em vez de gerente, para nomear o servidor responsável pela gestão do projeto de extensão. Na sequência, serão identificados os trâmites que devem ser realizados em cada fase, ao longo do desenvolvimento do projeto de 
extensão. Essas fases foram analisadas à luz da metodologia PMI. Essa explicação é necessária para melhor entendimento da seção Apresentação dos dados e Discussão que serão detalhados na seção 4 .

Na fase de iniciação, os coordenadores devem levantar os dados necessários para proposição do projeto, dentre eles, objetivos, área temática, caracterização do público atendido, recursos financeiros, humanos e físicos, justificativa, métodos e procedimentos de execução do projeto e possíveis parcerias. Esse documento inicial pode ser comparado ao Termo de Abertura do Projeto, documento definido pelo PMI (2012, p. 75) como "documento que formalmente autoriza a existência de um projeto e fornece ao gerente do projeto a autoridade necessária para aplicar recursos organizacionais às atividades do projeto". As partes interessadas, tanto internas (equipe executora), quanto externas (público atendido) à instituição, também são definidas nessa fase. Observa-se que o projeto de extensão deve ter um cronograma previsto de, no mínimo, 6 meses, devendo envolver discentes (voluntários ou bolsistas) na equipe executora.

Na fase de planejamento, o coordenador fica responsável por elaborar reuniões com a equipe para definir as atividades. Ele é caracterizado como "o processo de identificação e documentação das ações específicas a serem realizadas para produzir as entregas do projeto" (PMI, 2012, p. 572). O coordenador também deve levantar as possíveis aquisições necessárias (materiais e equipamentos) e identificar possíveis riscos. Também é importante estabelecer contato com o público a ser atendido (partes interessadas) para deliberar sobre as atividades propostas. Feito isso, o coordenador pode, caso necessário, ajustar o planejamento das ações já previstas no cronograma.

Na fase de execução, serão efetivamente executadas as atividades previstas no planejamento, "envolve coordenar recursos, gerenciar o engajamento das partes interessadas, e integrar e executar as atividades do projeto" (PMI, 2012, p. 595). Caso seja necessário, o coordenador pode alterar ou incluir atividades, alterando as atividades dentro do cronograma, não sendo possível a prorrogação do mesmo.

A fase de monitoramento e controle acontece ao longo de toda a execução do projeto, uma vez que o coordenador deve "acompanhar, analisar e ajustar o progresso e o desempenho do projeto; [...] a fim de identificar e corrigir desvios ou variações" (PMI, 2012, p. 613). A cada seis meses de execução do projeto, o coordenador deve incluir, no Sistema de 
Acompanhamento de Projetos (SAP), um relatório parcial das atividades executadas, elencando os resultados obtidos.

$\mathrm{Na}$ fase de encerramento, serão finalizadas todas as atividades do projeto. Para isto, o coordenador deve elaborar o relatório final com os resultados das ações desenvolvidas, a ser colocado no SAP em até 30 dias após o encerramento do cronograma. Após a entrega, os resultados são avaliados pela Chefia do Departamento de Extensão.

\section{METODOLOGIA}

A abordagem metodológica consistiu em uma pesquisa qualitativa e exploratória composta por revisão da literatura e estudo de caso. A base teórica é fundamentada de esforços realizados para utilizar a gestão de projetos como ferramenta de gerenciamento de projetos de extensão. As informações relativas ao estudo de caso foram levantadas, considerando a análise institucional, por meio de técnica de coleta de dados, e fundamentando-se nos princípios do Guia PMBOK (2). A análise documental efetuou-se adotando como objeto os documentos dos projetos, planilhas, relatórios, editais de seleção dos projetos de extensão e Sistema SAP, todos internos à instituição, considerando as dimensões e conceitos recomendados pelo PMBOK. O caso apresentado ilustra os conceitos apresentados na revisão, assim como a influência do aprendizado no desenvolvimento do planejamento e o papel da gestão de projetos.

Há uma legislação vigente que trata da obrigatoriedade de inclusão da extensão nos currículos da graduação. Desta forma, observou-se a necessidade de estudar e identificar possíveis falhas no gerenciamento dos projetos de extensão e, assim, propor possíveis melhorias no processo.

Primeiramente, foram levantados todos os documentos disponíveis, tanto arquivos eletrônicos, quanto físicos. Após a identificação do material, os documentos eletrônicos foram organizados por tipo e data, e os documentos físicos foram organizados em caixas, ao mesmo tempo em que dava prosseguimento à coleta dos dados quantitativos e qualitativos relevantes. A coleta de dados foi realizada em novembro de 2019, em documentos de projetos, planilhas, relatórios, editais de seleção dos projetos de extensão e Sistema SAP, registrados de janeiro de 2015 a outubro de 2019, no âmbito da UTFPR - Campus Cornélio Procópio.

Os relatórios dos projetos foram analisados um por um, manualmente. Para melhor caracterização e padronização da metodologia de levantamento desses dados, foram criadas 
planilhas com as informações dos projetos e de seus relatórios. Os dados pesquisados foram elencados no Quadro 1.

Quadro 1 - Dados levantados para a análise dos relatórios dos projetos

\begin{tabular}{|c|c|c|}
\hline $\begin{array}{c}\text { Informações } \\
\text { coletadas dos } \\
\text { Projetos: }\end{array}$ & $\begin{array}{c}\text { Informações sobre os Relatórios } \\
\text { dos Projetos: }\end{array}$ & $\begin{array}{l}\text { Possíveis respostas em } \\
\text { relação aos Relatórios }\end{array}$ \\
\hline Número do Projeto & Relatório parcial foi entregue? & Sim ou Não \\
\hline Título do Projeto & Relatório final foi entregue? & Sim ou Não \\
\hline Objetivo do Projeto & $\begin{array}{c}\text { Relatório entregue em } 30 \text { dias após o } \\
\text { término do projeto? }\end{array}$ & Sim ou Não \\
\hline Nome do Coordenador & Objetivos foram alcançados? & Sim ou Não ou Parcialmente \\
\hline $\begin{array}{l}\text { Departamento do } \\
\text { Coordenador }\end{array}$ & Houve alteração no cronograma? & Sim ou Não \\
\hline $\begin{array}{l}\text { Vínculo do } \\
\text { Coordenador }\end{array}$ & $\begin{array}{l}\text { Houve problemas no decorrer do } \\
\text { projeto? }\end{array}$ & Sim ou Não \\
\hline \multirow[t]{2}{*}{$\begin{array}{l}\text { Período de execução } \\
\text { do Projeto }\end{array}$} & Principais problemas ocorridos: & Campo Textual \\
\hline & $\begin{array}{l}\text { Foi realizada pesquisa de satisfação } \\
\text { com público atendido? }\end{array}$ & Sim ou Não \\
\hline
\end{tabular}

Fonte: Os autores (2019).

A primeira coluna do Quadro 1 refere-se às informações necessárias dos projetos, pois é a partir desses dados que se consegue analisar se as informações contidas nos relatórios são satisfatórias em relação aos objetivos propostos. Na coluna 2, constam as perguntas que buscaremos responder com base nos relatórios dos projetos. Por fim, na coluna 3, estão as possíveis respostas para as perguntas da coluna 2, sendo que o item "Principais problemas ocorridos" é um campo de texto que preenchemos conforme as observações feitas pelo coordenador no relatório final do projeto. 


\section{Caracterização do objeto de estudo}

A instituição pesquisada é a Universidade Tecnológica Federal do Paraná - Campus de Cornélio Procópio, cidade localizada na região norte do estado do Paraná. A UTFPR é a primeira universidade tecnológica no Brasil, tendo sido criada a partir do Centro Federal de Educação Tecnológica do Paraná (CEFET-PR). Como a origem desse centro é a Escola de Aprendizes Artífices, fundada em 1909, a UTFPR herdou uma longa e expressiva trajetória em educação profissional.

A UTFPR tem como objetivos disponibilizar cursos de graduação e pós-graduação e promover projetos de pesquisa e extensão com qualidade e excelência. Atualmente, está distribuída em 13 campi no estado do Paraná. Cada campus mantém cursos planejados de acordo com a necessidade da região onde está inserido. A instituição tem como missão desenvolver a educação tecnológica de excelência por meio do ensino, pesquisa e extensão, interagindo de forma ética, sustentável, produtiva e inovadora com a comunidade para o avanço do conhecimento e da sociedade, tendo como visão ser modelo educacional de desenvolvimento social e referência na área tecnológica.

A missão da extensão na UTFPR é proporcionar educação de excelência, articulando o ensino e a pesquisa e promovendo o desenvolvimento social e tecnológico sustentável da comunidade, com a visão de ser referência na formação e interação do ser humano social e profissional no âmbito educativo, cultural, científico e tecnológico (UFTPR, [20--], p. 4)

Em relação à estrutura organizacional da extensão na UTFPR, ela é compreendida pela PróReitoria de Relações Empresariais e Comunitárias (PROREC) e pela Diretoria de Extensão (DIREXT). A função desses órgãos é normatizar e dar suporte à extensão na UTFPR, por meio de editais do fomento de bolsas e auxílio para participação e desenvolvimento de projetos. No âmbito dos campi, temos o Departamento de Extensão (DEPEX). A Figura 1 representa de forma generalista a disposição da estrutura da extensão na UTFPR. 
Figura 1 - Estrutura da Extensão na UTFPR

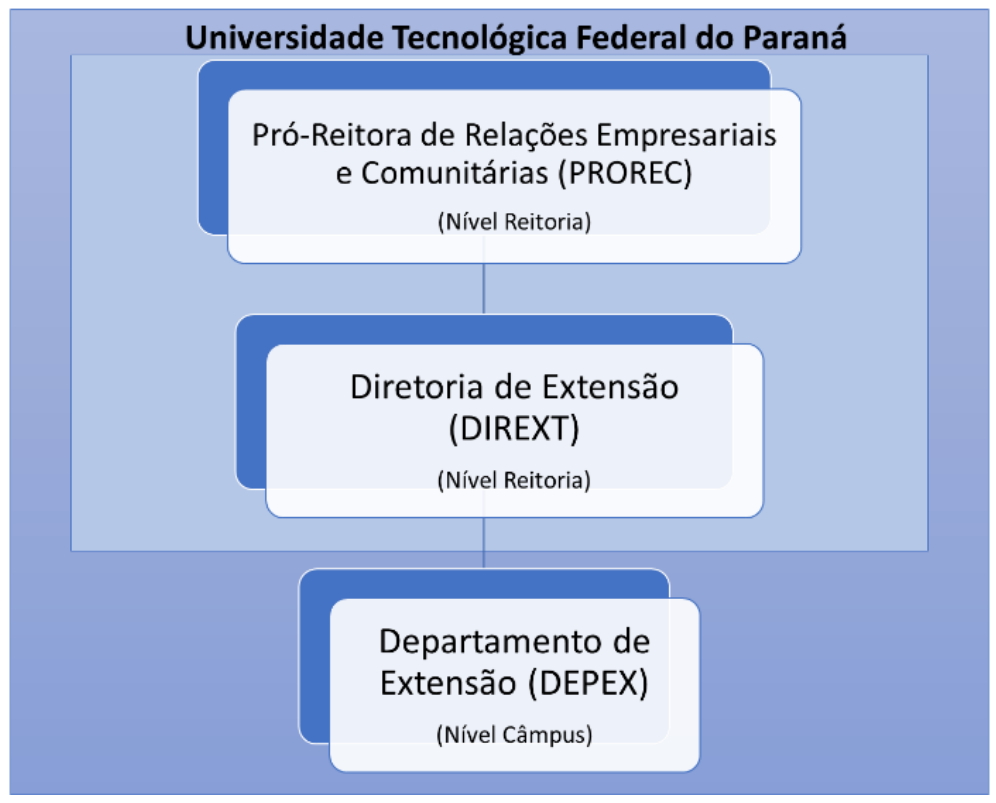

Fonte: Os autores (2019).

O DEPEX do Campus Cornélio Procópio atua desde 2009, quando da sua criação. Esse departamento é responsável por registrar, gerenciar, apoiar e fomentar as ações de extensão locais.

\section{APRESENTAÇÃO DOS DADOS E DISCUSSÃO}

Nesta seção, apresentamos os resultados da pesquisa após a análise dos documentos, registros e relatórios dos projetos de extensão. A coleta dos dados foi realizada em novembro de 2019, em que foram analisados dados de janeiro de 2015 a outubro de 2019. Na sequência, são apresentados os resultados e discussão.

\section{Análise documental}

Para análise documental, foram acessadas planilhas de controle e gerenciamentos dos registros dos projetos, relatórios finais dos projetos, editais de seleção dos projetos de extensão e Sistema SAP, que foi implantado em março de 2019 (anteriormente, utilizava-se a documentação física para tramitação e registro do projeto). Para melhor desenvolvimento da análise documental, procurou-se, primeiramente, entender os requisitos para proposição dos projetos e o processo para homologação dos mesmos. Após, segue-se com a análise dos dados coletados. 


\section{Identificação dos documentos e processo de homologação}

A homologação dos projetos de extensão pode ocorrer por fluxo contínuo ou edital de seleção de projetos de extensão. Em ambas as modalidades, toda a tramitação do projeto é atualmente feita por intermédio do SAP. Na opção de fluxo contínuo, o responsável pelo DEPEX recebe o projeto já recomendado pela chefia imediata do proponente e encaminha para um avaliador externo à UTFPR-CP, em que serão avaliados requisitos pré-determinados. Após o retorno da avaliação externa, o projeto é avaliado pelo responsável pelo DEPEX, o qual faz uma média das duas notas e retorna o resultado ao coordenador. Após a aprovação do projeto, inicia-se o planejamento detalhado e a execução, conforme exposto na seção 2.3. No fluxo contínuo, não há distribuição de bolsas, somente de recursos financeiros, quando há disponibilidade financeira e após aprovação da planilha de gastos.

O edital para seleção de projetos de extensão é outra forma para homologação dos projetos de extensão, que é gerido pela PROREC e DIREXT, e abre inscrições anualmente, em que podem concorrer servidores de todos os campi da UTFPR, desde que tenham, no mínimo, a titulação de mestre. $\mathrm{O}$ edital tem como principal objetivo estimular os servidores a atuar na extensão universitária e engajar estudantes de graduação com o propósito de exercitar a indissociabilidade entre ensino, pesquisa e extensão, otimizando a capacidade de socialização do conhecimento da universidade, visando à transformação da sociedade e vice-versa.

Os projetos são avaliados por três pareceristas e o currículo lattes do proponente também é pontuado. Após ser gerada a média das notas, é feita a classificação geral dos projetos. Os projetos classificados estão aptos a receber bolsas para os discentes e/ou ajuda financeira, conforme disponibilidade de orçamento.

Na sequência, serão exibidos os principais dados da extensão na UTFPR-CP.

\section{Análise dos dados numéricos}

O DEPEX da UTFPR-CP registrou, de janeiro de 2015 a outubro de 2019, um total de 283 projetos aprovados, contabilizando, aproximadamente, 1.185 estudantes voluntários envolvidos nas equipes executoras, e 46 projetos contemplados com bolsas.

Inicia-se a análise dos dados pelo perfil dos coordenadores dos projetos. De todos os 283 projetos homologados, $56 \%$ foram coordenados por homens e $44 \%$ por mulheres. Sendo que 96\% desses coordenadores eram docentes e somente $4 \%$ eram técnicos administrativos, um 
número baixo, considerando que, aproximadamente, 33\% dos servidores da UTFPR-CP são técnicos administrativos e $67 \%$, docentes.

A Figura 2 exibe o número de projetos de extensão registrados entre janeiro de 2015 e outubro de 2019, o número de voluntários, bem como o número de bolsistas que atuaram na equipe executora destes projetos. Os registros dos projetos de extensão vieram crescendo ano após ano desde 2015, já que nesse ano foram 35 projetos registrados e, em 2018, foram 76, um aumento de mais de 100\%. Até outubro de 2019 foram registrados 73 projetos, ou seja, somente em 10 meses se aproximou do número de registro do ano anterior, indicando que, provavelmente, esse número seria ainda maior em 2019. Em relação aos voluntários, houve também um aumento crescente ano a ano, entretanto destaca-se que, em 2018, houve aumento de 532\% no número de voluntários envolvidos, se comparado ao ano de 2015, o que demonstra crescimento do interesse dos alunos em fazer extensão. Em relação aos bolsistas, 2016 foi o pior ano, com somente 5 bolsas, e 2017 o melhor ano, com 13 bolsas, um aumento de $260 \%$ em relação ao ano anterior. Até outubro de 2019, mesmo com a redução orçamentária da universidade, a UTFPR-CP disponibilizou 12 bolsas.

Figura 2 - Dados dos Projetos de Extensão

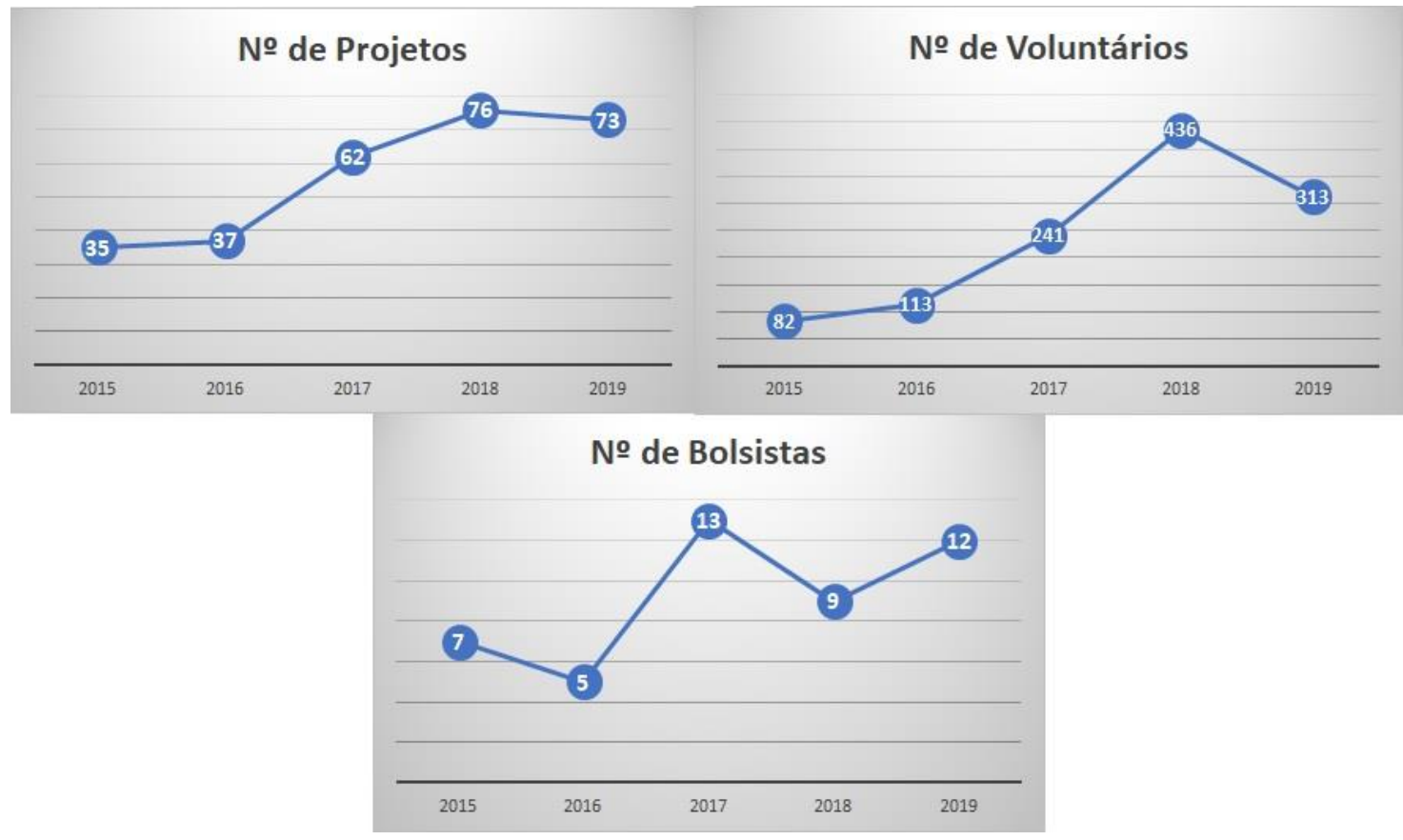

Fonte: Os autores (2019). 
Na Tabela 1, observa-se a distribuição dos projetos de extensão por área temática. Assim, é possível identificar que a maioria dos projetos está voltada para a área da Educação, enquanto Meio Ambiente é a área que tem o menor número, pois somente um projeto foi realizado no período pesquisado. Em 2018, houve elevação no número de projetos voltados à Cultura, um aumento de, aproximadamente, $400 \%$ em relação aos anos anteriores. Os projetos voltados para a área da Saúde obtiveram destaque em 2017 e 2019.

Tabela 1 - Projetos de Extensão por Área Temática

\begin{tabular}{lllllll}
\hline Área Temática & $\mathbf{2 0 1 5}$ & $\mathbf{2 0 1 6}$ & $\mathbf{2 0 1 7}$ & $\mathbf{2 0 1 8}$ & $\mathbf{2 0 1 9}$ & $\begin{array}{l}\text { Total por } \\
\text { área }\end{array}$ \\
\hline Comunicação & 0 & 0 & 2 & 4 & 2 & 8 \\
Cultura & 5 & 3 & 4 & 18 & 10 & 40 \\
Direitos Humanos e Justiça & 2 & 2 & 2 & 5 & 4 & 15 \\
Educação & 13 & 17 & 20 & 28 & 28 & 106 \\
Meio Ambiente & 0 & 0 & 0 & 1 & 0 & 1 \\
Saúde & 6 & 7 & 21 & 7 & 18 & 59 \\
Tecnologia e Produção & 9 & 8 & 13 & 13 & 10 & 53 \\
Trabalho & 0 & 0 & 0 & 0 & 1 & 1 \\
\hline Número de Projetos anuais & $\mathbf{3 5}$ & $\mathbf{3 7}$ & $\mathbf{6 2}$ & $\mathbf{7 6}$ & $\mathbf{7 3}$ & $\mathbf{2 8 3}$ \\
\hline
\end{tabular}

Fonte: Os autores (2019).

No Gráfico 1, temos a classificação decrescente dos registros dos projetos em relação ao departamento ao qual o coordenador está vinculado. Destaca-se o DACHS com 76 projetos (173\%) a mais que o segundo colocado, e os departamentos acadêmicos (DACHS, DAELE, DAMAT, DACOM, DAMEC e DACIN) possuem 96\% dos projetos registrados. O DACOM foi o departamento com a maior queda no número de projetos, 7 projetos registrados em 2015 e somente 3 em 2019. Os outros dez departamentos não acadêmicos que propuseram projetos tiveram um número muito pequeno de projetos homologados, sendo o maior número registrado em 2018. 


\section{Gráfico 1 - Número de projetos por Departamento}

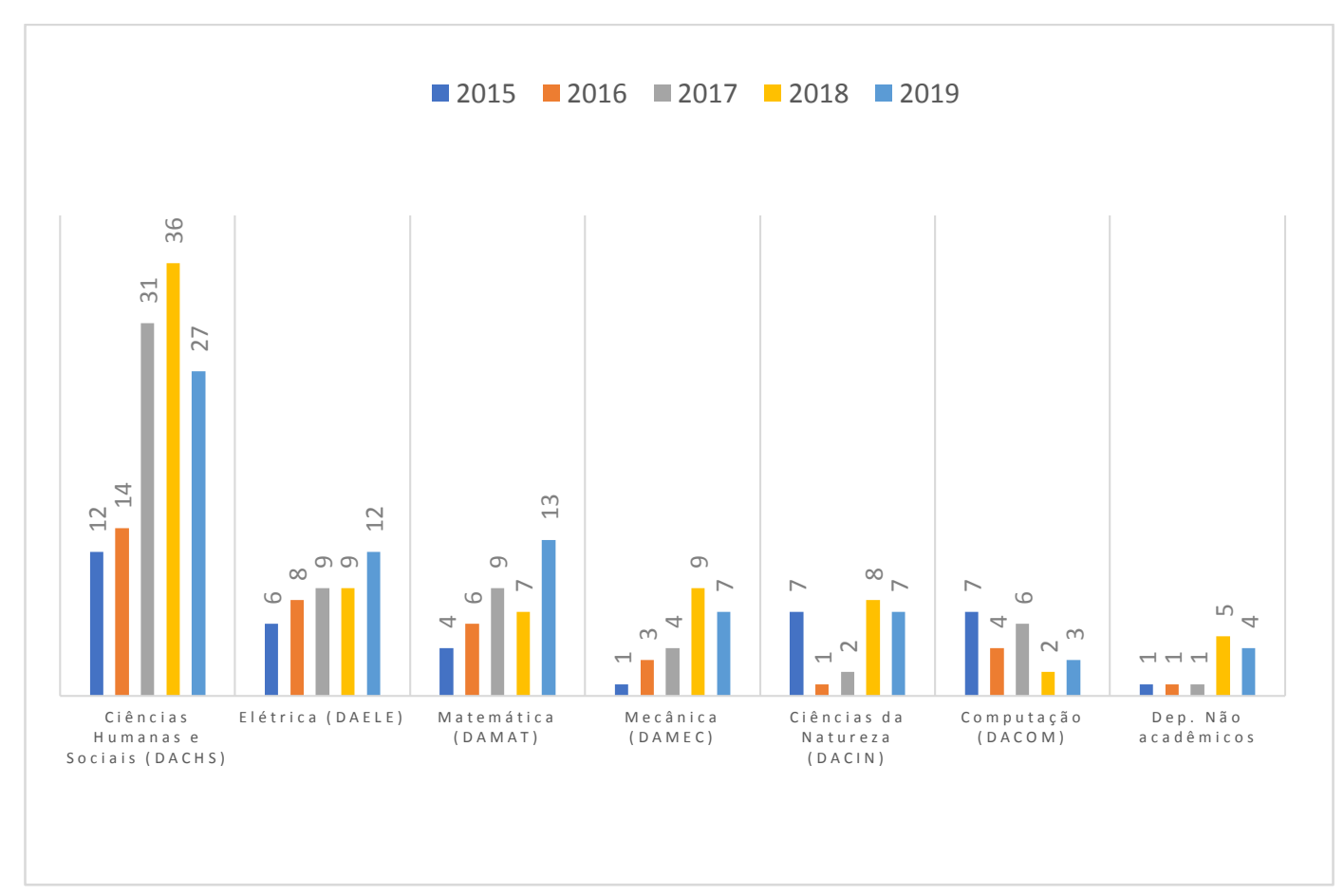

Fonte: Os autores (2019).

Os dados apresentados na Figura 2, na Tabela 1 e no Gráfico 1 trazem a dimensão numérica da extensão na UTFPR-CP. A seguir, trataremos dos resultados e discussão.

\section{RESULTADOS E DISCUSSÃO}

Nos documentos e relatórios dos projetos, foram levantados os dados elencados no Quadro 1. A partir desse levantamento, pôde-se criar o Quadro 2, e com base nesses dados foram feitas quatro descobertas relevantes em relação aos projetos de extensão aprovados na UTFPR-CP. 
Quadro 2 - Relatórios dos Projetos de Extensão

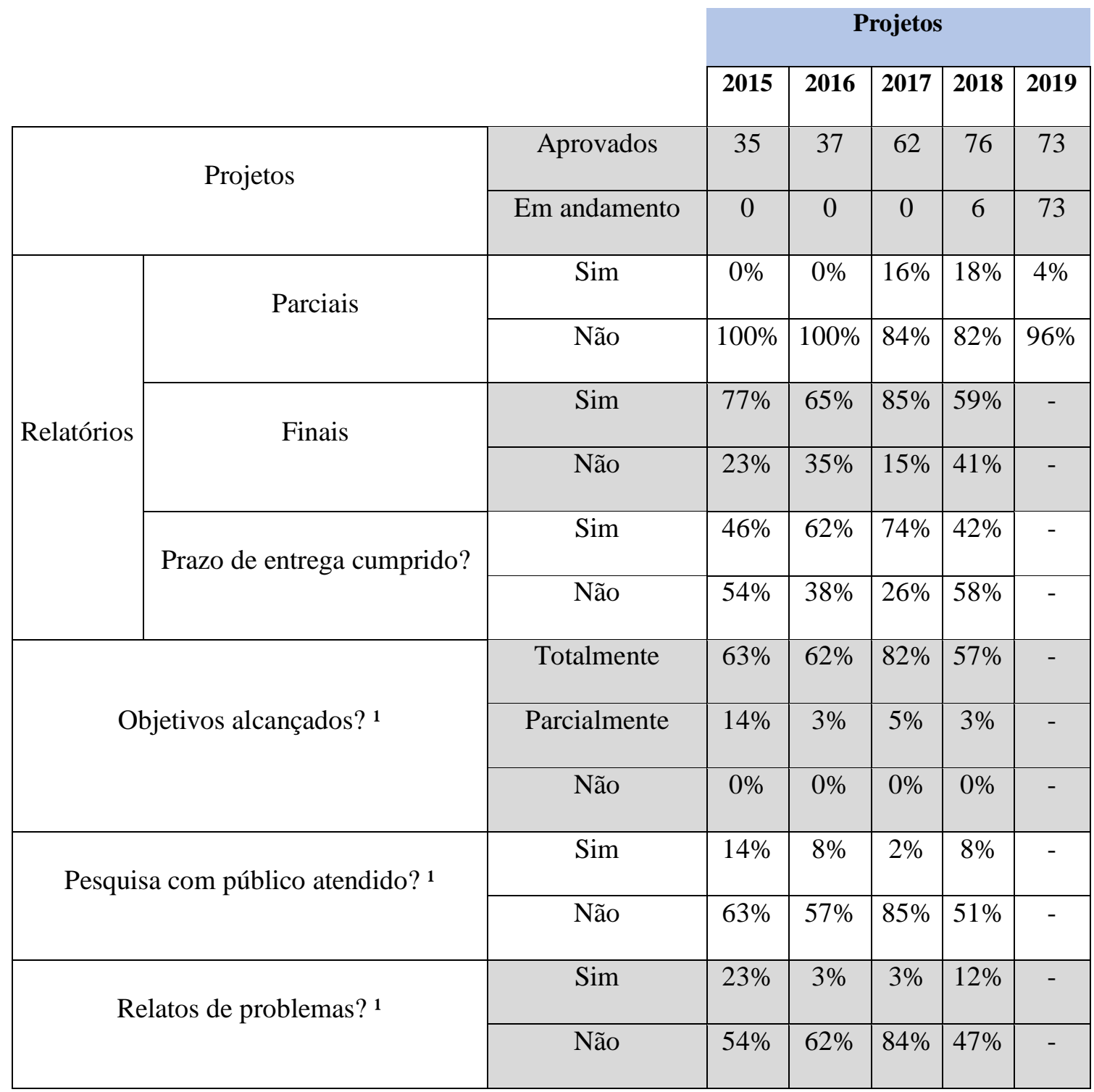

Fonte: Os autores (2019).

Nota: ${ }^{1}$ Os dados foram retirados dos relatórios finais entregues dos projetos de extensão, que se referem a $77 \%$ em 2015, 65\% em 2016, 85\% em 2017 e 59\% em 2018.

A primeira descoberta refere-se ao número elevado de projetos registrados sem relatórios parciais. No Quadro 2, observa-se que, em 2015 e 2016, 100\% dos coordenadores de projetos não entregaram o relatório parcial. Os índices de não entrega de relatórios parciais continuaram altos em 2017 e 2018, pois foram de 84\% e 82\%, respectivamente. Em 2019, nenhum projeto foi concluído, mas somente $4 \%$ dos projetos registrados apresentou algum relatório parcial até outubro de 2019. Esses dados são relevantes, pois os coordenadores de projetos de extensão possuem muitas outras atividades além da coordenação dos projetos; dessa forma, o relatório parcial funcionaria como um meio de monitorar o andamento de 
projeto, e, caso necessário, efetuar as devidas mudanças, pois segundo o PMI (2017, p. 107) "o monitoramento contínuo fornece à equipe de gerenciamento do projeto uma compreensão clara da saúde do projeto, identificando quaisquer áreas que possam requerer atenção especial". Ademais, para escrever o relatório parcial, o coordenador, além de ir a campo, deve promover reuniões com a equipe, a fim de identificar possíveis problemas e soluções, fazendo com que todas as partes interessadas (equipe e participantes), quando possível, também participem das tomadas de decisão, assim, aumenta-se o engajamento.

A segunda descoberta trata do alto índice de projetos sem relatório final. Em 2016 e 2018, respectivamente, $35 \%$ e $33 \%$ dos coordenadores de projetos não entregaram relatório final. Em 2017, obteve-se o melhor resultado, uma vez que somente $13 \%$ dos projetos não apresentaram o relatório final. A não entrega desse documento pode acarretar vários problemas para os coordenadores, pois sem ele não é possível comprovar que o projeto aconteceu e nem quais foram os resultados obtidos. No caso de projetos que receberam bolsa, o relatório final é o documento que presta contas das atividades realizadas. É na fase de encerramento que "as informações do projeto ou da fase são arquivadas, o trabalho planejado é concluído e os recursos organizacionais são liberados para utilização em novos empreendimentos" (PMI, 2017, p. 634). A falta do relatório final também impossibilita a identificação dos problemas e dos resultados obtidos, impedindo a geração de certificados que comprovem a participação no projeto, o que porventura pode desmotivar as partes interessadas (equipe e participantes), já que eles não receberão o comprovante de participação ou atuação no projeto.

A terceira descoberta refere-se à falta de qualquer tipo de pesquisa relacionada à satisfação ou aprendizado do público atendido ou das partes interessadas. Do total de projetos (54\%) que entregaram o relatório final em 2018, somente $8 \%$ realizaram algum tipo de pesquisa com o público atendido. Informações relativas às opiniões dos participantes atendidos e da equipe executora podem auxiliar o coordenador na melhoria do projeto de extensão e, possivelmente, diminuir a evasão dos participantes. Pois, de acordo com o PMI (2017, p. 504) "a habilidade do gerente de projetos e da equipe para identificar corretamente e engajar todas as partes interessadas de maneira apropriada pode fazer a diferença entre o êxito e o fracasso do projeto". Corroborando essa ideia, temos o trabalho desenvolvido por Silva et al. (2013) em que criaram atividades lúdicas com crianças de oito a dez anos para investigar o aprendizado sobre nutrição e, dessa forma, identificar se as ações propostas foram eficazes. Ainda demonstrando a importância da pesquisa em relação ao aprendizado dos alunos voluntários, 
Floriano et al. (2017) realizaram um estudo para identificar as percepções da comunidade acadêmica de uma universidade federal do Rio Grande do Sul, sobre as ações de extensão realizadas na instituição.

$\mathrm{Na}$ quarta descoberta, destacam-se os relatórios finais entregues com atraso (44\% do total), com poucos dados, ou poucos detalhados, que dificultam a identificação dos dados nos relatórios finais. Sendo que os principais problemas relatados pelos coordenadores nos relatórios finais são taxas elevadas de evasão dos participantes, falta de local para a realização das atividades e escassez de recursos financeiros.

Portanto, tanto os relatórios finais quanto os parciais são documentos imprescindíveis, tanto para os coordenadores dos projetos, quanto para a gestão da universidade como um todo, uma vez que esses documentos apresentam dados que podem servir para o planejamento financeiro da extensão e possível disponibilização de novos ambientes para uso da extensão.

\section{CONSIDERAÇÕES FINAIS}

O objetivo geral do estudo foi analisar o gerenciamento dos projetos de extensão em um campus de uma universidade federal, buscando identificar as etapas em que ocorrem mais problemas em relação a gestão dos projetos.

A partir da análise dos documentos e relatórios dos projetos pode-se concluir que os projetos de extensão na UTFPR-CP são executados e alcançam seus objetivos gerais, no entanto, observou-se que não há uma grande preocupação dos coordenadores quanto ao controle das atividades e documentação de monitoramento e encerramento dos projetos de extensão. Assim, verificou-se que as atividades que deveriam ser realizadas nas fases de monitoramento e controle e encerramento não estão satisfatórias. Para minimizar esse problema, sugere-se que coordenadores e membros da equipe do projeto façam treinamentos e capacitações a fim de melhorar o controle das atividades dos projetos e documentação como relatórios finais e parciais.

Quanto a limitações, tem-se um grande número de documentos impressos que precisaria ser verificado, o que demandou tempo. Devido à distância entre os campi e a disponibilidade dos pesquisadores, essa pesquisa foi realizada somente no campus Cornélio Procópio da UTFPR. Contudo, o método utilizado também poderá ser replicado em outro campus, pois os campi têm realidades diferentes, podendo apresentar resultados diferentes. Assim, seria importante descobrir o que está deficitário na gestão dos projetos de extensão em cada campus. 
Para trabalhos futuros, sugere-se uma pesquisa de campo, junto aos coordenadores, os membros da equipe e até mesmo aos participantes, para identificar os problemas e propor possíveis ferramentas ou processos para solucioná-los.

Por fim, esse trabalho cumpriu seu objetivo de analisar o gerenciamento dos projetos de extensão na UTFPR-CP, pois foram apontadas as etapas que precisam de maior atenção. Esse é um passo importante, visto que, conforme citado anteriormente, a extensão na educação superior brasileira se integra à matriz curricular, com o objetivo de promover a interação transformadora entre as universidades e a sociedade. A extensão atua na produção e na prática do conhecimento, em permanente articulação com o ensino e a pesquisa, e uma gestão eficaz desses projetos de extensão trarão resultados ainda mais satisfatórios a todas as partes interessadas.

\section{REFERÊNCIAS}

BRASIL. Constituição (1988). Constituição da República Federativa do Brasil. Brasília, SF: Senado Federal, 1988.

BRASIL. Lei $n^{\circ} 5.540$, de 28 de novembro de 1968. Fixa normas de organização e funcionamento do ensino superior e sua articulação com a escola média, e dá outras providências. Disponível em: https://www2.camara.leg.br/legin/fed/lei/1960-1969/lei-554028-novembro-1968-359201-publicacaooriginal-1-pl.html. Acesso em: 9 out. 2019.

BRASIL. Lei $n^{\circ} 13.005$, de 25 de junho de 2014. Aprova o Plano Nacional de Educação PNE e dá outras providências. Disponível em: http://www.planalto.gov.br/ccivil_03/_ato2011-2014/2014/lei/113005.htm. Acesso em: 9 out. 2019.

CLEMENTS, J. P.; GIDO, J. Gestão de projetos. 5. ed. São Paulo: Cengage Learning, 2013.

FLORIANO, M. D. P. et al. Extensão universitária: a percepção de acadêmicos de uma universidade federal do Estado do Rio Grande do Sul. Em Extensão, Uberlândia, v. 16, n.1, p. 9-35, jan.-jun. 2017.

FORPROEX - FÓRUM DE PRÓ-REITORES DAS INSTITUIÇÕES PÚBLICAS DE EDUCAÇÃO SUPERIOR BRASILEIRAS. Política Nacional de Extensão Universitária. 2012. Disponível em: https://www.ufmg.br/proex/renex/images/documentos/2012-07-13Politica-Nacional-de-Extensao.pdf. Acesso em: 9 out. 2019.

PMI - PROJECT MANAGEMENT INSTITUTE. Um guia do conhecimento em gerenciamento de projetos (Guia PMBOK). 6. ed. Newtown Square, Pensilvânia: PMI, 2017. 
QUARTI, D. M.; ZILLI, J. C. Gerenciamento de projetos na gestão organizacional: aplicação dos fundamentos do PMBOK em uma associação empresarial. Revista Foco, Vila Velha, v. 12 , n. 2, p. 147-167, mar.jun. 2019. Doi: 10.28950/1981223x_revistafocoadm/2019.v12i2.645.

SILVA, M. X. da et al. Projeto piloto: considerações de alunos do ensino fundamental sobre método de educação alimentar. Em Extensão, Uberlândia, v. 12, n.2, p. 51-64, jul.-dez. 2013.

UTFPR - UNIVERSIDADE TECNOLÓGICA FEDERAL DO PARANÁ. Diretrizes de Extensão da Universidade Tecnológica Federal do Paraná. Disponível em: http://portal.utfpr.edu.br/documentos/relacoes-empresariais-e-

comunitarias/dirext/regulamentos/diretrizes-da-extensao-na-utfpr. Acesso em: 9 out. 2019.

UTFPR - UNIVERSIDADE TECNOLÓGICA FEDERAL DO PARANÁ. Resolução no 69/2018 - COGEP, retificada em $1^{\circ}$ de outubro de 2018. Disponível em: http://www.utfpr.edu.br/documentos/conselhos/cogep/resolucoes/resolucoes-2018/resolucao069-2018-cogep-regulamento-de-registro-e-de-inclusao-das-atividades-de-extensao-noscurriculos-dos-cursos-de-graduacao-da-utfpr.pdf. Acesso em: 9 out. 2020.

Submetido em 28 de janeiro de 2020.

Aprovado em 16 de abril de 2020. 